\title{
A 10-Year Monitoring of Soil Properties Dynamics and Soil Fertility Evaluation in Chinese Hickory Plantation Regions of Southeastern China
}

Jin Jin

Zhejiang A\&F University

Luoqi Wang

Zhejiang A\&F University

Karin Muller

The New Zealand Institute for Plant \& Food Research Limited

Jiasen Wu ( $\nabla$ jswu@zafu.edu.cn )

Zhejiang A\&F University

Hailong Wang

Foshan University

Keli Zhao

Zhejiang A\&F University

Frank Berninger

University of Eastern Finland

Weijun Fu

Zhejiang A\&F University

\section{Research Article}

Keywords: Chinese hickory, Spatio-temporal variation, Soil properties, Soil fertility, Anthropogenic factors

Posted Date: June 27th, 2021

DOI: https://doi.org/10.21203/rs.3.rs-644353/v1

License: (1) (1) This work is licensed under a Creative Commons Attribution 4.0 International License.

Read Full License

Version of Record: A version of this preprint was published at Scientific Reports on December 1st, 2021. See the published version at https://doi.org/10.1038/s41598-021-02947-z. 
1 A 10-year monitoring of soil properties dynamics and

2 soil fertility evaluation in Chinese hickory plantation

3 regions of southeastern China

4

5

7

8

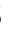

Jin Jin ${ }^{a, 1}$, Luoqi Wang ${ }^{a, 1}$, Karin Muller ${ }^{b}$, Jiasen $W_{u^{a,}}{ }^{,}$, Hailong Wang $^{c}$, Keli Zhao ${ }^{a}$, Frank Berninger ${ }^{d}$, Weijun Fu ${ }^{a, e,{ }^{*}}$

a State Key Laboratory of Subtropical Silviculture, Zhejiang A\&F University, Hangzhou, 311300, China

b The New Zealand Institute for Plant \& Food Research Limited, Ruakura Research Centre, Private Bag, Hamilton, 3123, New Zealand

'Biochar Engineering Technology Research Center of Guangdong Province, School of Environmental and Chemical Engineering, Foshan University, Foshan, 528000, China

dDepartment of Environmental and Biological Sciences, University of Eastern Finland, PO Box 111, Joensuu, 80101, Finland

e Zhejiang Provincial Key Laboratory of Carbon Cycling in Forest Ecosystems and Carbon Sequestration, Zhejiang A\&F University, Lin'an 311300, China

${ }^{1}$ These two authors contributed equally to this work.

*Corresponding authors: jswu@zafu.edu.cn; fuweijun@zafu.edu.cn

Tel.: +86-571-611-02592; Fax.: +86-571-610-81397

Number of text pages: $19 \quad$ Number of figures: 5 Number of tables: 2

Submitted to: Scientific Reports

Type of paper: Regular paper (Original full-length research paper) 


\section{Abstract}

Long-term monitoring shows intensive management can significantly change soil properties and cause soil degradation. Knowledge related to the spatio-temporal variation of soil properties and their influencing factors are important for nutrient management of economic forest plantation. Here, we conducted an intensive field investigation in Chinese hickory plantation to clarify the spatial and temporal variation of soil properties and its influencing factors, and to evaluate the change of soil fertility. The results showed that the soil pH and soil organic carbon (SOC) significantly increased from 2008 to 2018, while available $N$ significantly decreased from 2008 to 2018 . The semi-variance revealed that except available $\mathrm{P}$, the spatial dependencies of soil properties increased from 2008 to 2018. An increasing south-north gradient was found for soil available $\mathrm{N}$, available $\mathrm{P}$, available $\mathrm{K}$ and $\mathrm{SOC}$ and a decreasing south-north gradient was found for soil pH. One-way ANOVA analysis showed that the change of soil properties from 2008 to 2018 was mainly influenced by anthropogenic factors. The average soil fertility in the whole area was at a medium level from 2008 to 2018. These change of soil properties can provide a reference basis for monitoring the effects of intensive management on soil environment.

Keywords: Chinese hickory; Spatio-temporal variation; Soil properties; Soil fertility; Anthropogenic factors;

\section{Introduction}

Soil plays an important role in ecosystem processes that control nutrient cycling. Long-term monitoring of soil properties contributes to sustainable agricultural development, improving food quality and safety, as well as to maintaining or improving soil fertility levels and avoiding soil degradation ${ }^{1}$. Numerous studies ${ }^{2-4}$ have been carried out in terrestrial ecosystems to study the factors affecting soil properties. These factors can be categorised into external factors, such as altitude, climate, topography, land use and management, internal factors, such as parent material, porosity, microbe ${ }^{5-12}$. Since 1980, with the implementation of China's reform and opening-up policy, Chinese agriculture has changed with mechanized farming and chemical fertilization increasing ${ }^{13}$. And long-term intensive agricultural management significantly changed soil $\mathrm{pH}$, nutrient status, microbial biomass and community composition ${ }^{14-17}$. In addition, over-or inappropriate fertilization has caused various environmental problems, such as air pollution, water pollution, soil erosion, soil acidification and biodiversity loss ${ }^{18-20}$. This not only causes economic losses, but also has a negative impact on environmental safety and human health ${ }^{21-23}$.

China, the largest developing country in the world, has experienced a rapid shift from natural vegetation lands into economic forests since the 1960s, due to an expanding human population. Economic forests are widely distributed in China, with a total area of 20.57 million ha, accounting for 9\% of the national forest area $^{24}$. Thus, economic forests are critical to promoting economic development and participating in $\mathrm{C}$ balance at regional and national scales. However, such large-scale land use change would markedly alter soil physio-chemical and biological properties ${ }^{25}$. For example, inappropriate management practices (pure forest management, deep ploughing and pruning) have led 
to a reduction of soil microorganisms and the imbalance of soil nutrients ${ }^{26-29}$. Therefore, understanding the effect of economic forest management practices on soil properties is much of importance to achieve sustainable use of forest soil.

Chinese hickory is a unique edible nut and woody oil species that distributed in the Tianmu mountain in Zhejiang province of southeastern China. Because of its unique taste and high nutritional value, the area of Chinese hickory has reached 93,300 ha with a total yield of $31,500 \mathrm{t}$ in $2018^{30,31}$. For the purpose of improving the yield of Chinese hickory, farmers have adopted intensive agricultural management with extensive application of chemical fertilizer. In addition, it was necessary to remove undergrowth (herbicide or artificial weeding) in order to harvest Chinese hickory fruits (Fig. S1ab). Not surprisingly, long-term intensive management resulted in soil acidification and negative effects on soil fertility and hickory tree health ${ }^{32,33}$. Therefore, it is necessary to better understand the spatio-temporal variation of soil properties in Chinese hickory plantation regions in order to guide sustainable Chinese hickory management. Although previous studies related to soil properties in Chinese hickory plantation regions were reported ${ }^{34-36}$, the long-term dynamics and driving factors of soil fertility is limited. The objectives of our study were to (1) investigate the spatio-temporal variation of soil properties under long-term intensive management; (2) to explore the environmental factors influencing the changes in soil properties; (3) to evaluate the change of soil fertility in Chinese hickory plantation regions.

\section{Results}

Descriptive statistics. After logarithmic and Box-cox transformations, the soil properties all passed the K-S test $\left(K-S_{P}>0.05\right)$ (Table 1). The coefficient of variation $(\mathrm{CV})$ values ranged from $10 \%$ to $130 \%$. According to $\mathrm{Fu}$ et al reported ${ }^{37}, \mathrm{CV}<10 \%$, between 10 and $90 \%$, and $>90 \%$ indicate low, moderate and high variabilities, respectively. With the exception of available phosphorus (AP) concentrations for 2008 and 2018, which were highly variable, all other soil properties were moderately variable. The average $\mathrm{pH}$ was significantly higher in 2018 than that in $2008(P<0.05)$. From 2008 to 2018, the average available nitrogen (AN) concentration declined by $38 \%$ (Table 1). The concentration of available potassium (AK) in 2018 was significantly higher than in 2013 (Fig. S2). The variation ranges of AN and AP concentrations were significantly narrower in 2018 than in 2008 (Table 1). The soil pH was negatively correlated with AP and soil organic carbon (SOC) concentrations in 2008 and 2013 ( $P<0.01$, Fig. 2). However, soil pH, AP and SOC were not correlated in 2018 (Fig. 2). Correlations between AN, AP, AK and SOC in 2008-2018 were positive (Fig. 2).

Spatial cluster and spatial outlier analysis. The local indicators of spatial correlation (LISA) maps (Fig. 3) indicated significant positive spatial autocorrelations for all soil properties $(P<0.05)$. The local Moran's $I$ results identified high-high spatial clusters of soil $\mathrm{pH}$ in the middle region of the study area, while low-low clusters of soil $\mathrm{pH}$ were distributed in the northwest region of the study area (Daoshi town) from 2008 to 2018 (Fig. 3a-c). On the contrary, high-high clusters of AN, AP and SOC were mainly located in the northwest region of study area (Fig. 3d-i, m-o). Meanwhile, high-high clusters of AK concentration shifted from northwest to northeast of the study area from 2013 to 2018 (Fig. 3k-l). 
To further describe the spatial structures of soil properties in 2008, 2013 and 2018, we calculated the semi-variances function of each study variable. and selected the best-fitted models and their related parameters (Table 2). The spatial dependencies $\left(\mathrm{C}_{0} / \mathrm{C}_{0}+\mathrm{C}\right)$ for soil $\mathrm{pH}, \mathrm{AN}, \mathrm{AK}$ and SOC were moderate and strong for AK in 2008 and 2013. The spatial autocorrelation for SOC was improved from 2008 to 2018 (Table 2). The ranges of soil properties varied from $0.16 \mathrm{~km}$ (AP) to $40.7 \mathrm{~km}(\mathrm{pH})$ in 2008 , and from $0.13 \mathrm{~km}$ (AN) to $23.73 \mathrm{~km}$ (AP) in 2018 , respectively.

122

The spatio-temporal distribution maps of soil properties were revealed by the ordinary Kriging interpolation method based on the semi-variance models for 2008, 2013 and 2018. The concentrations of AN, AP, AK and SOC had similar spatial distribution patterns (Fig. 4d-o), with high values mainly located in the northwest and northeast parts of the study area, while low values in the central and south regions. However, $\mathrm{pH}$ values showed an opposite spatial distribution pattern with a gradually increasing trend from north to south (Fig. 4a-c). Generally speaking, the spatial distributions of soil properties were similar to the above spatial clusters identified by local Moran's I (Fig. 3). Meanwhile, soil properties varied considerably from 2008 to 2018 (Fig. S3). The pH value generally increased, among which the $\mathrm{pH}$ value increased in Daoshi town, and Qingliangfeng town, while the $\mathrm{pH}$ value decreased in Tuankou town (Fig. S3a-c). The AN concentrations decreased from $213.82 \mathrm{mg} \mathrm{kg}^{-1}$ in 2008 to $43.50 \mathrm{mg} \mathrm{kg}^{-1}$ in 2018, among which the greatest decrease occurred in Daoshi town and Qingliangfeng town (Fig. S3d-f).

Control factors for soil properties. One way ANOVA analysis indicated that MAP and MAP have a significant influence on the change of pH (Table S2). What's more, altitude has significant influence on AP and SOC. However, most of soil properties was significantly influenced by anthropogenic factors such as fertilization, weeding, and harvesting methods (Table S2). This showed that the difference of comprehensive management mode, such as management method and intensity, will lead to the change of soil properties.

Soil fertility evaluation. The improved Nemerow method was used to evaluate the soil integrated fertility index (IFI) of Chinese hickory plantation, and the results were shown in Fig. 5. The soil fertility of Chinese hickory plantation was at medium level, but the IFI value decreased year by year, which was $\mathrm{IFI}=1.14$ in 2008 , IFI=1.08 in 2013 and $\mathrm{IFI}=1.06$ in 2018 , respectively. The IFI value in Daoshi town, Qingliangfeng town and Heqiao town and Tuankou town was relatively large in 2008

(Fig. 5a). However, in some areas of Daoshi town, soil fertility dropped from moderate to low in 2013 (Fig. 5b). In 2018, most parts of the study area declined to the low fertility level (IFI <0.9) (Fig. 5c). And compared with the previous two periods, Qingliangfeng town, Heqiao town and Tuankou town had the great reductions. Overall, soil fertility was at a moderate level in whole area during 2008-2018, but there were regional differences.

\section{Discussion}

Soil $\mathrm{pH}$ is a fundamental property that has significantly influences on numerous soil physical, chemical, biological properties and processes that affect plant growth and is therefore considered to be 
a key soil variable 38,39 . Our study showed that after 5 years intensive management caused significantly soil acidification (Table 1). This may be caused by excessive fertilizer application, atmospheric acid deposition, and fruit removal of base ions. Previous studies showed that long-term excessive application of nitrogen fertilizer will lead to the loss of calcium, magnesium and other base ions, directly leading to the production of $\mathrm{H}^{+}$in the soil ${ }^{39,40}$. $\mathrm{SO}_{2}$ produced by industrial development and fossil burning and nitrogen oxides produced by agricultural production aggravate atmospheric acid deposition. What' more, other studies have shown that pecan harvesting removes base ions from the soil, leading to a drop in soil pH. However, compared with 2013, the $\mathrm{pH}$ value of the soil increased significantly in 2018 (Table 1). The increase in pH in 2018 was mainly contribute to the application of lime. Lime is a widely used worldwide to improve soil $\mathrm{pH}$ value and increase crop yields. Adequate lime input can raise the soil $\mathrm{pH}$ to a normal level, thereby eliminating the influence of $\mathrm{Al}$ and $\mathrm{Mn}$ on crops, and offsetting the leaching loss of base cations, thus increasing the soil $\mathrm{pH}^{41}$.

According to the classification levels of the State Soil Survey Service of China (SSSSC 1996) ${ }^{42}$, the concentration of AN more than $120 \mathrm{mg} \mathrm{kg}^{-1}$ can be considered as high level. In our study, the average concentration of AN were $190.08 \mathrm{mg} \mathrm{kg}^{-1}$ and $171.12 \mathrm{mg} \mathrm{kg}^{-1}$ in 2008 and 2013, respectively (Table 1). At the same time, Kriging interpolation analysis showed that high levels of AN were observed in almost the whole study area in 2008 and 2013 (Fig. 4). In the past decades, the massive consumption of nitrogen fertilizer has insured China produce enough grain to feed its growing population ${ }^{43}$. However, previous studies ${ }^{44,45}$ have revealed that the efficiency of nitrogen fertilizer will decrease when the application rate exceeded the threshold ( $\mathrm{AN}>120 \mathrm{mg} \mathrm{kg}^{-1}$ ). Lei $(2018)^{46}$ showed that excessive accumulation of nitrogen in the soil would cause an increase in the incidence of dry rot in Chinese hickory plants, which could lead to plant death (Fig. S4). In addition, excessive nitrogen input significantly increased the leaching of reactive nitrogen and gas emissions, causing environmental pollution. Therefore, farmers reduced the amount of nitrogen they applied to keep the Chinese hickory sustainable in 2018. According to LISA map, the distribution of AP presented a serious polarization phenomenon, while the high-high clusters were mainly distributed in the northeastern and the low-low clusters were mainly distributed in the southeastern of study area (Fig. 3g-i). Zhao et al ${ }^{47}$ suggested that Chinese hickory plants might be P-deficient when soil available phosphorus was lower than 10.0 $\mathrm{mg} \mathrm{kg}{ }^{-1}$. More serious, the average AP in the whole study area was less than $5 \mathrm{mg} \mathrm{kg}^{-1}$ from 2008 to 2018 indicating a severe phosphorus deficiency (Table S1). This was related to the relatively low phosphorus concentration derived from the parent materials. But fundamentally speaking, the long-term high temperature and heavy rain in the south will cause serious phosphorus leaching. Therefore, farmers should pay attention to the dynamic change of AP and apply phosphorus fertilizer according to local conditions ${ }^{48}$. Tong et $\mathrm{al}^{49}$ reported that when AK was higher than $100 \mathrm{mg} \mathrm{kg}^{-1} \mathrm{in} \mathrm{soil,}$ it could meet the requirements of carbohydrate transportation and fat synthesis during the growth period of Chinese hickory nuts. However, the $\mathrm{AK}<100 \mathrm{mg} \mathrm{kg}^{-1}$ were widely found in Daoshi town, Qingliangfeng town and Tuankou town (Fig. 4l). Chinese hickory growing areas in these towns shared a common characteristic: it used to grow on steep slopes greater than 40 degrees and had serious soil erosion. This will cause potassium loss with water runoff or leaching to deep layers. Therefore, potassium should be replenished in time in these towns. Overall, in order to satisfy the nutrient requirement of the growth of Chinese hickory, it is necessary to apply soil experiment formula fertilizer. 
SOC is commonly considered as an important indicator for evaluating soil fertility ${ }^{50-53}$. It can not only maintain and release soil nutrients, but also improve the physical structure of soil ${ }^{54-56}$. In our study, the concentration of SOC has significantly increased from $18.5 \mathrm{~g} \mathrm{~kg}^{-1}$ to $21.4 \mathrm{~g} \mathrm{~kg}^{-1}$ from 2008 to 2018 (Fig. S2). The CV in the concentration of SOC from 2013 to 2018 increased during the study period (Table 1). The concentration of SOC in Daoshi town had the largest variability (Fig. S3m-o). According to field surveys, a large number of Chinese hickory plantation in Daoshi town have been abandoned in recent years, resulting in a thicker ground litter cover and understory. Previous studies showed that root-derived $\mathrm{C}$ additions were particularly effective in increasing the concentration of SOC $^{57-59}$. This could be the main reason for the increase of SOC in Daoshi town. Table 2 showed that SOC in 2008 and 2013 had moderate spatial dependence based on the "Nugget-to-sill" ratio, on the contrary, SOC showed a strong spatial dependence in 2018. This indicated that the spatial dependence of soil carbon in Chinese hickory plantation was more affected by internal factors than external factors with the increase of intensive agricultural management years. Moreover, Table S2 showed that among the external factors, fertilization, weeding and harvesting methods all had extremely significant influence on SOC. Herbicide application was a common management method to reduce understory vegetation. The traditional method of collecting Chinese hickory fruit required that the ground be kept clean, so herbicides have been the first choice for farmers to clear undergrowth in the past (Fig S1a-b). However, in recent years, due to the intensification of soil erosion, farmers have gradually changed their harvesting methods from knocking to laying nets (Fig. S1a-d). This method reduced the application of herbicide and increased the input of exogenous $\mathrm{C}$, which was beneficial to improve the content of SOC.

\section{Materials and methods}

Study area. The study area is located in Lin'an city $\left(29^{\circ}-31^{\circ} \mathrm{N}, 118^{\circ}-120^{\circ} \mathrm{E}\right)$, Zhejiang province, southeastern China (Fig. 1). It is the largest production area of Chinese hickory, accounting for from 300 to 375 culm ha-1, with an average diameter at breast height (DBH) of $12 \mathrm{~cm}$ and an average tree height of $8 \mathrm{~m}^{61}$. The area is characterized by subtropical monsoon climate with four distinct seasons, with the annual average temperature of $16^{\circ} \mathrm{C}$ and annual precipitation of $1628 \mathrm{~mm}$. The annual average daylight hours are $1774 \mathrm{~h}$ with $235 \mathrm{~d}$ frost-free ${ }^{62}$. It has undulating topography with an elevation range of $150-1000 \mathrm{~m}^{63}$. The soil is derived from 7 major types of parent material, which include sandstone, sand shale, slate, phyllite, royolite, granite and quartz porphyry ${ }^{64,65}$. During the period of 2008-2010, 600-800 $\mathrm{kg} \mathrm{ha}^{-1}$ of a compound fertilizer ( $\mathrm{N}: \mathrm{P}_{2} \mathrm{O}_{5}: \mathrm{K}_{2} \mathrm{O}$, 15:15:15) was applied every year ${ }^{31}$. From 2010 to 2018 , the amount of fertilizer applied was reduced to $150-300 \mathrm{~kg} \mathrm{ha}^{-1}$ per year. Typically, herbicide application and mowing were the main methods for controlling understory vegetation.

Field sampling and laboratory analysis. A grid of $1 \mathrm{~km} \times 1 \mathrm{~km}$ was used, based on Chinese hickory plantation distribution in the Lin'an city. A total of 209 sample sites were established in 2008. For each site, a $20 \mathrm{~m} \times 20 \mathrm{~m}$ plot was established. Five subsoil samples with a depth of 0-30 cm were collected according to the "Z" shape, which were further mixed into one soil sample, with a weight of $1 \mathrm{~kg}$. For 
each sampling year, 209 soil samples were collected in situ in July of 2008, 2013 and 2018, respectively (Fig. 1). A portable global positioning system (GPS) was used to record the coordinates and altitude of each sampling location. Information on parent materials and forest age were recorded in 2008. The survey related to management measures (including fertilization, weeding and harvesting methods) of the Chinese hickory plantation regions was also carried out every 5 years. Annual average precipitation and annual average temperature information comes from the weather forecast network.

All soil samples were air-dried and sieved to 2-mm nylon mesh. A portion of each soil sample was ground with an agate mortar to pass the $0.149 \mathrm{~mm}$ nylon mesh, and sealed in an enclosed polyethylene bag. Soil $\mathrm{pH}$ was determined using an aqueous suspension at soil/water $(w / v)$ ratio of 1:2.5. The soil AN was measured by a diffusion method. Soil AP and AK of soil samples were determined by $\mathrm{Mo}-\mathrm{Sb}$ colorimetry and $\mathrm{NH}_{4} \mathrm{OAc}$ extraction flame photometer, respectively. $\mathrm{SOC}$ was determined by the $\mathrm{K}_{2} \mathrm{Cr}_{2} \mathrm{O}_{7}-\mathrm{H}_{2} \mathrm{SO}_{4}$ digestion, and titration with ammonium sulfate iron $\left(\mathrm{Fe}\left(\mathrm{NH}_{4}\right)_{2}\left(\mathrm{SO}_{4}\right)_{2} \cdot 6 \mathrm{H}_{2} \mathrm{O}\right)$ solution.

Data analysis. Descriptive statistics and difference tests. The maximum, minimum, range, mean, standard deviation (SD), CV, kurtosis, skewness and significance test of sample indexes for 2008, 2013 and 2018 were presented. Test of normality for soil pH, AN, AP, AK, SOC was performed by the Kolmogorov-Smirnov (K-S) test ${ }^{66}$. None of the data were normally distributed. Therefore, the Box-Cox transformation of $\mathrm{pH}$ (2008 and 2013) and AK (2018) were performed to meet the assumption of normality using Matlab r2019a software. All other data were log transformed using SPSS (version 21.0). Kernel density estimation was used to estimate the distribution of the soil properties in all sample plots (package stats in R statistical software 4.0.0). One-way ANOVA was used to compare the differences in soil properties in 2008, 2013 and 2018. Pearson correlation analysis was used to identify the correlations between soil $\mathrm{pH}, \mathrm{AN}, \mathrm{AP}, \mathrm{AK}$ and $\mathrm{SOC}^{37}$. An alpha level of 0.05 for significance testing was used in all statistical analyses, unless mentioned otherwise.

Spatial autocorrelation analyses. Spatial autocorrelation analysis is a statistical method to measure the cluster degree of spatial variables ${ }^{67}$. Moran's $I$ is a commonly used index of spatial autocorrelation, which reflects the similarity between adjacent samples ${ }^{68,69}$. The global Moran's I was used to describe the soil properties autocorrelation feature over the entire regions (See Supplementary material, Text S1 for detailed information).

Geostatistical analysis. The semi-variance (or variogram) is widely used in geostatistics to quantitatively describe the spatial variability of environmental variables, and this relationship was expressed through an effective variogram model, which can further provide input parameters for spatial interpolation of kriging ${ }^{70}$ (See Supplementary material, Text $\mathbf{S 2}$ for detailed information).

The ordinary Kriging method can be used to derive the optimal linear unbiased estimate of spatial variables ${ }^{71}$. The models that fit the semivariogram best according to the regression coefficient were determined. For the kriging interpolation, the transformed soil properties data were used. The ordinary kriging method was used to draw a spatial 
distribution map of soil properties and soil quality grade with ArcGIS desktop 10.7 (Esri Inc., Redlands, CA, USA).

Soil fertility evaluation. The calculation of Integrated Fertility Index (IFI) comprises three steps: (i) the selection of indicators, (ii) the calculation of the individual fertility index $\left(\mathrm{IFI}_{i}\right)$, and (iii) the calculation of IFI. The soil $\mathrm{pH}, \mathrm{AN}, \mathrm{AP}, \mathrm{AK}$ and SOC were used in the calculations. To calculate the IFI the following equation was used:

$\mathrm{IFI}_{i}= \begin{cases}\frac{x}{x_{a}} & x<x_{a} \\ 1+\frac{\left(x-x_{a}\right)}{\left(x_{b}-x_{a}\right)} & x_{a} \leq x \leq x_{b} \\ 2+\frac{\left(x-x_{b}\right)}{\left(x_{c}-x_{b}\right)} & x_{a} \leq x \leq x_{b} \\ 3 & x>x_{c}\end{cases}$

Where $\mathrm{IFI}_{i}$ is the individual fertility index; $x$ is the measured value of each attribute ${ }^{72} ; x_{a} x_{b}$ and $x_{c}$ are the upper and lower limits of each classification standard based on forest soils in Zhejiang (Table S1).

The final step was to calculate IFI using the improved Nemerow Quality Index equation:

$$
\mathrm{IFI}=\sqrt{\frac{1}{2}\left(\mathrm{IFI}_{i \text { ave }}^{2}+\mathrm{IFI}_{i \text { min }}^{2}\right)} \times\left(\frac{n-1}{n}\right)
$$

Where IFI is the soil integrated fertility index; $\mathrm{IFI}_{\text {iave }}$ is the average values for the individual fertility indices; $\mathrm{IFI}_{i \min }$ is the minimum value for the individual fertility indices; $n$ is the number of soil properties $^{73}$. The degree of IFI was classified as follows: IFI $<0.9$; low, $0.9 \leq$ IFI $<1.8$; moderate, 1.8 $\leq \mathrm{IFI}<2.7$; high, and IFI $\leq 2.7$; very high.

\section{References}

1 Brevik, E. C. \& Sauer, T. J. The past, present, and future of soils and human health studies. SOIL 1, 35-46, doi:10.5194/soil-1-35-2015 (2015).

2 Liu, X., Zhang, W., Zhang, M., Ficklin, D. L. \& Wang, F. Spatio-temporal variations of soil nutrients influenced by an altered land tenure system in China. Geoderma 152, 23-34, doi:10.1016/j.geoderma.2009.05.022 (2009).

3 Tao, H. et al. Quantifying influences of interacting anthropogenic-natural factors on trace element accumulation and pollution risk in karst soil. Sci. Total Environ. 721, doi:10.1016/j.scitotenv.2020.137770 (2020).

4 Xie, E. et al. Spatiotemporal variations in soil organic carbon and their drivers in southeastern China during 1981-2011. Soil Till. Res. 205, doi:10.1016/j.still.2020.104763 (2021).

5 Abegaz, A., Winowiecki, L. A., Vågen, T. G., Langan, S. \& Smith, J. U. Spatial and temporal dynamics of soil organic carbon in landscapes of the upper Blue Nile Basin of the Ethiopian 
Highlands. Agr. Ecosyst. Environ. 218, 190-208, doi:10.1016/j.agee.2015.11.019 (2016).

Jobbágy, E. G. \& Jackson, R. B. The vertical distribution of soil organic carbon and its relation to climate and vegetation. Ecol. Appl. 10, 423-436, doi:10.1890/1051-0761(2000)010[0423:TVDOSO]2.0.CO;2 (2000).

7 Liu, H. et al. Interactive effects of microplastics and glyphosate on the dynamics of soil dissolved organic matter in a Chinese loess soil. Catena 182, doi:10.1016/j.catena.2019.104177 (2019).

8 Orgill, S. E. et al. Parent material and climate affect soil organic carbon fractions under pastures in south-eastern Australia. Soil Res. 55, 799-808, doi:10.1071/SR16305 (2017).

9 Song, C., Wang, E., Han, X. \& Stirzaker, R. Crop production, soil carbon and nutrient balances as affected by fertilisation in a Mollisol agroecosystem. Nutr. Cycl. Agroecosys. 89, 363-374, doi:10.1007/s10705-010-9401-5 (2011).

10 Tang, M. et al. Elevational is the main factor controlling the soil microbial community structure in alpine tundra of the Changbai Mountain. Sci. Rep-uk. 10, doi:10.1038/s41598-020-69441-w (2020).

11 Zhang, Y. et al. Soil organic carbon and total nitrogen stocks as affected by vegetation types and altitude across the mountainous regions in the Yunnan Province, south-western China. Catena 196, doi:10.1016/j.catena.2020.104872 (2021).

12 Zhu, J., Wu, A. \& Zhou, G. Spatial distribution patterns of soil total phosphorus influenced by climatic factors in China's forest ecosystems. Sci. rep-uk. 11, 5357, doi:10.1038/s41598-021-84166-0 (2021).

13 Liu, D., Gong, Q.W., Yang, W.J. The evolution of farmland protection policy and optimization path from 1978 to 2018. China Rural Economy 12, 37-51 (2018) (in Chinese).

14 Cai, X. et al. Effects of conversion from a natural evergreen broadleaf forest to a Moso bamboo plantation on the soil nutrient pools, microbial biomass and enzyme activities in a subtropical area. Forest Ecol. Manag. 422, 161-171, doi:10.1016/j.foreco.2018.04.022 (2018). $\mathrm{Fu}$, W. et al. Spatial variation of biomass carbon density in a subtropical region of Southeastern China. Forests 6, 1966-1981, doi:10.3390/f6061966 (2015).

16 Fu, W., Fu, Z., Zhao, K., Tunney, H. \& Zhang, C. Variation of soil P and other nutrients in a long-term grazed Grassland P experiment field. Arch. Agron. Soil Sci. 60, 1459-1466, doi:10.1080/03650340.2014.891018 (2014).

17 Wang, H. et al. Effects of long-term application of organic fertilizer on improving organic matter content and retarding acidity in red soil from China. Soil Till. Res. 195, doi:10.1016/j.still.2019.104382 (2019).

18 Chen, S., Lin, B., Li, Y. \& Zhou, S. Spatial and temporal changes of soil properties and soil fertility evaluation in a large grain-production area of subtropical plain, China. Geoderma 357, doi:10.1016/j.geoderma.2019.113937 (2020).

19 Keesstra, S. et al. Effects of soil management techniques on soil water erosion in apricot orchards. Sci. Total Environ. 551-552, 357-366, doi:10.1016/j.scitotenv.2016.01.182 (2016).

20 Liu, M. et al. Nitrogen leaching greatly impacts bacterial community and denitrifiers abundance in subsoil under long-term fertilization. Agri. Ecosyst. Environ. 294, doi:10.1016/j.agee.2020.106885 (2020).

21 Bogunovic, I., Trevisani, S., Seput, M., Juzbasic, D. \& Durdevic, B. Short-range and regional 
spatial variability of soil chemical properties in an agro-ecosystem in eastern Croatia. Catena 154, 50-62, doi:10.1016/j.catena.2017.02.018 (2017).

22 De Notaris, C., Rasmussen, J., Sørensen, P. \& Olesen, J. E. Nitrogen leaching: A crop rotation perspective on the effect of $\mathrm{N}$ surplus, field management and use of catch crops. Agr. Ecosyst. Environ. 255, 1-11, doi:10.1016/j.agee.2017.12.009 (2018).

23 Weier, K. L. Nitrogen use and losses in agriculture in subtropical Australia. Fertil. Res. 39, 245-257, doi:10.1007/BF00750253 (1994).

24 Zhu Y.C. et al. Analysis of the economic forest development status, existing problems and countermeasure in China. China Forestry Economy 03, 89-91 (2020).

25 Han, C. et al. Effects of three coniferous plantation species on plant-soil feedbacks and soil physical and chemical properties in semi-arid mountain ecosystems. For. Ecosyst. 8, doi:10.1186/s40663-021-00281-4 (2021).

26 Fang, X. et al. Forest-type shift and subsequent intensive management affected soil organic carbon and microbial community in southeastern China. Eur. J. Forest Res. 136, 689-697, doi:10.1007/s10342-017-1065-0 (2017).

27 Li, Y. et al. Long-term intensive management effects on soil organic carbon pools and chemical composition in Moso bamboo (Phyllostachys pubescens) forests in subtropical China. Forest Ecol. Manag. 303, 121-130, doi:10.1016/j.foreco.2013.04.021 (2013).

28 Wang, H. et al. Converting evergreen broad-leaved forests into tea and Moso bamboo plantations affects labile carbon pools and the chemical composition of soil organic carbon. Sci. Total Environ. 711, doi:10.1016/j.scitotenv.2019.135225 (2020).

29 Xue, L. et al. Long term effects of management practice intensification on soil microbial community structure and co-occurrence network in a non-timber plantation. Forest Ecol. Manag. 459, doi:10.1016/j.foreco.2019.117805 (2020).

30 Jia-Sen, W., Jin-Fang, Q., Zhi-Peng, T., Jian-Qin, H. \& Ke-Li, Z. Changes in soil organic carbon and soil microbial functional diversity of Carya cathayensis plantations under intensive managements. The journal of applied ecology. 25 (2014).

31 Shen, Y.F. et al. Spatial-temporal variation of soil fertility in Chinese walnut (Carya cathayensis) Plantation. Scientia Silvae Sinicae 52, 1-12 (2016) (in Chinese).

32 Gao, Z., Liu, Z.Q. \& Li, Y.N. Soil and water loss status and ecological restoration countermeasures in Lin'an city, Zhejiang Province. Research. Soil Water Conse. 21, 327-331 (2014) (in Chinese).

33 Huang, X.Z. et al. Comparison on soil physical and chemical properties at different vertical zones of Carya cathayensis stands. J. Zhejiang Forestry Sci.Technol. 30, 23-27 (2010) (in Chinese).

34 Li, G. et al. Examining hickory plantation expansion and evaluating suitability for it using multitemporal satellite imagery and ancillary data. Appl. Geogr. 109, doi:10.1016/j.apgeog.2019.102035 (2019).

35 Zhang, M. et al. Difference in $\mathrm{pH}$ value and nutrient and bacterial diversity in the carya cathayensis forest soil under different management models. Biodivers. Sci. 26, 611-619, doi:10.17520/biods.2017268 (2018).

Dong, J.H. et al. Soil Fertility of Carya cathayensis plantations on different geological strata. J. Zhejiang Forestry Sci. Technol. 38, 14-20 (2018) ( in Chinese). 
37 Fu, W. J., Jiang, P. K., Zhou, G. M. \& Zhao, K. L. Using Moran's i and GIS to study the spatial pattern of forest litter carbon density in a subtropical region of southeastern China. Biogeosciences 11, 2401-2409, doi:10.5194/bg-11-2401-2014 (2014).

38 Fu, C. et al. Spatial interpolation of orchard soil $\mathrm{pH}$ using soil type and planting duration as auxiliary information. Pedosphere 30, 628-637, doi:10.1016/S1002-0160(18)60045-1 (2020).

39 Liu, Z. P., Shao, M. A. \& Wang, Y. Q. Large-scale spatial interpolation of soil pH across the Loess Plateau, China. Environ. Earth Sci. 69, 2731-2741, doi:10.1007/s12665-012-2095-Z (2013).

40 Hao, T. et al. Impacts of nitrogen fertilizer type and application rate on soil acidification rate under a wheat-maize double cropping system. J. Environ. Manage. 270, doi:10.1016/j.jenvman.2020.110888 (2020).

41 Xu, D., Carswell, A., Zhu, Q., Zhang, F. \& de Vries, W. Modelling long-term impacts of fertilization and liming on soil acidification at Rothamsted experimental station. Sci.Total Environ. 713, doi:10.1016/j.scitotenv.2019.136249 (2020).

42 State Soil Survey Service of China (SSSC). (1996) Dataset of National Soil Survey of China. China Agriculture Press, Beijing 103-122 (in Chinese).

43 Liu, H. et al. Impact of herbicide application on soil erosion and induced carbon loss in a rubber plantation of Southwest China. Catena 145, 180-192, doi:10.1016/j.catena.2016.06.007 (2016).

44 Geisseler, D. \& Scow, K. M. Long-term effects of mineral fertilizers on soil microorganisms A review. Soil Biol. Biochem. 75, 54-63, doi:10.1016/j.soilbio.2014.03.023 (2014).

45 Zhao, H., Li, X. \& Jiang, Y. Response of nitrogen losses to excessive nitrogen fertilizer application in intensive greenhouse vegetable production. Sustainability-Basel 11, doi:10.3390/su11061513 (2019).

46 Lei, Y.C.et al. Relationship between soil chemical properties and canker disease of Carya cathayensis. Zhejiang A\&F University (2018) (in Chinese).

47 Zhao, W.M. et al. Soil phosphorus status and leaching risk analysis of walnut forest land in Lin 'an. Acta agriculturae Zhejiangensis, 26, 154-158. (2014).

48 Liu, Z. et al. A simple assessment on spatial variability of rice yield and selected soil chemical properties of paddy fields in South China. Geoderma 235-236, 39-47, doi:10.1016/j.geoderma.2014.06.027 (2014).

49 Tong, G.P. et al. Seasonal changes of soil and leaf nutrient levels in a Carya cathayensis orchard. J. Zhejiang forestry U. 26, 516-521 (2009).

$50 \mathrm{Li}$, J., Zhang, D. \& Liu, M. Factors controlling the spatial distribution of soil organic carbon in Daxing'anling Mountain. Sci. rep-uk. 10, doi:10.1038/s41598-020-69590-y (2020).

51 Li, P., Wang, Q., Endo, T., Zhao, X. \& Kakubari, Y. Soil organic carbon stock is closely related to aboveground vegetation properties in cold-temperate mountainous forests. Geoderma 154, 407-415, doi:10.1016/j.geoderma.2009.11.023 (2010).

52 Tiessen, H., Cuevas, E. \& Chacon, P. The role of soil organic matter in sustaining soil fertility. Nature 371, 783-785, doi:10.1038/371783a0 (1994).

$53 \mathrm{Xu}, \mathrm{H}$. \& Zhang, C. Investigating spatially varying relationships between total organic carbon contents and $\mathrm{pH}$ values in European agricultural soil using geographically weighted regression. Sci. Total Environ. 752, doi:10.1016/j.scitotenv.2020.141977 (2021). 

Estimation of soil organic matter content by modeling with artificial neural networks. Geoderma 350, 46-51, doi:10.1016/j.geoderma.2019.04.044 (2019).

55 Stockmann, U. et al. Global soil organic carbon assessment. Glob. Food Secur. 6, 9-16, doi:10.1016/j.gfs.2015.07.001 (2015).

56 Wood, S. A., Tirfessa, D. \& Baudron, F. Soil organic matter underlies crop nutritional quality and productivity in smallholder agriculture. Agr. Ecosyst. Environ. 266, 100-108, doi:10.1016/j.agee.2018.07.025 (2018).

57 Jackson, R.B. et al. The ecology of soil carbon: pools, vulnerabilities, and biotic and abiotic controls. Annu. Rev. Ecol. Evol. S. 48, 419-445. doi: 10.1146/annurev-ecolsys-112414-054234 (2017).

58 Midwood, A. J. et al. Importance of drive-row vegetation for soil carbon storage in woody perennial crops: A regional study. Geoderma 377, doi:10.1016/j.geoderma.2020.114591 (2020).

59 Schillaci, C. et al. Spatio-temporal topsoil organic carbon mapping of a semi-arid Mediterranean region: The role of land use, soil texture, topographic indices and the influence of remote sensing data to modelling. Sci. Total Environ. 601-602, 821-832, doi:10.1016/j.scitotenv.2017.05.239 (2017).

60 Xi, Z., Lu, D., Liu, L. \& Ge, H. Detection of drought-induced hickory disturbances in western Lin an county, China, using multitemporal Landsat imagery. Remote Sens-basel. 8, doi:10.3390/rs8040345 (2016).

61 Wu, J., Lin, H., Meng, C., Jiang, P. \& Fu, W. Effects of intercropping grasses on soil organic carbon and microbial community functional diversity under Chinese hickory (Carya cathayensis Sarg.) stands. Soil Res. 52, 575-583, doi:10.1071/SR14021 (2014).

$62 \mathrm{Wu}, \mathrm{W}$. et al. Soil organic carbon content and microbial functional diversity were lower in monospecific Chinese hickory stands than in natural Chinese hickory-broad-leaved mixed forests. Forests 10, doi:10.3390/f10040357 (2019).

$63 \mathrm{Wu}, \mathrm{J}$. et al. Effect of 26 years of intensively managed Carya cathayensis stands on soil organic carbon and fertility. Sci. World J. 2014, doi:10.1155/2014/857641 (2014).

64 Micheli, E., Schad, P., Spaargaren, O., Dent, D. \& Wrb, I. W. World reference base for soil resources: 2006: a framework for international classification, correlation and communication. (World reference base for soil resources: 2006: a framework for international classification, correlation and communication, 2006).

65 Dong, L.L. et al. Changes of soil physical-chemical properties derived from different parent materials/rocks in Karst Mountain. Chinese J. Soil Sci. 03, 471-474 (2008) (in Chinese).

66 Dai, W. et al. Spatial variation of organic carbon density in topsoils of a typical subtropical forest, southeastern China. Catena 167, 181-189, doi:10.1016/j.catena.2018.04.040 (2018).

67 Bocquet-Appel, J. P. \& Bacro, J. N. Isolation by distance, trend surface analysis, and spatial autocorrelation. Hum. biol. an international record of research 65, 11-27 (1993).

68 Fu, W., Zhao, K., Zhang, C. \& Tunney, H. Using Moran's I and geostatistics to identify spatial patterns of soil nutrients in two different long-term phosphorus-application plots. J. Plant Nutr. Soil Sci. 174, 785-798, doi:10.1002/jpln.201000422 (2011).

69 Zhao, K. et al. Spatial variations of concentrations of copper and its speciation in the soil-rice 
system in Wenling of southeastern China. Environ. Sci. Pollut. R. 21, 7165-7176, doi:10.1007/s11356-014-2638-9 (2014).

70 Zhao, K. et al. Risk assessment, spatial patterns and source apportionment of soil heavy metals in a typical Chinese hickory plantation region of southeastern China. Geoderma 360, doi:10.1016/j.geoderma.2019.114011 (2020).

71 Chen, T. et al. Identification of trace element sources and associated risk assessment in vegetable soils of the urban-rural transitional area of Hangzhou, China. Environ. Pollut. 151, 67-78, doi:10.1016/j.envpol.2007.03.004 (2008).

72 Kan, W.J., Wu, Q.T. A preliminary study on a quantitative and comprehensive method for evaluating soil fertility. Chinese J. Soil Sci. 06, 245-247 (1994) (in Chinese).

73 Yang, M., Mouazen, A., Zhao, X. \& Guo, X. Assessment of a soil fertility index using visible and near-infrared spectroscopy in the rice paddy region of southern China. Eur. J. Soil Sci. 71, 615-626, doi:10.1111/ejss.12907 (2020).

\section{Acknowledgements}

This work was financially supported by the Natural Science Foundation of Zhejiang Province (No. LY20C160004). The authors declare no conflict of interest.

\section{Author contributions}

J.J., and L.W., analyzed statistically the data, composed figures and wrote the manuscript. J.W., K.Z., and W.F., designed and supervised all the experiment. K.M., H.W., and F.B., contributed to the data interpretation and to the revision of the final report. All authors contributed substantially to revisions.

\section{Competing interests}

The authors declare no competing interests. 


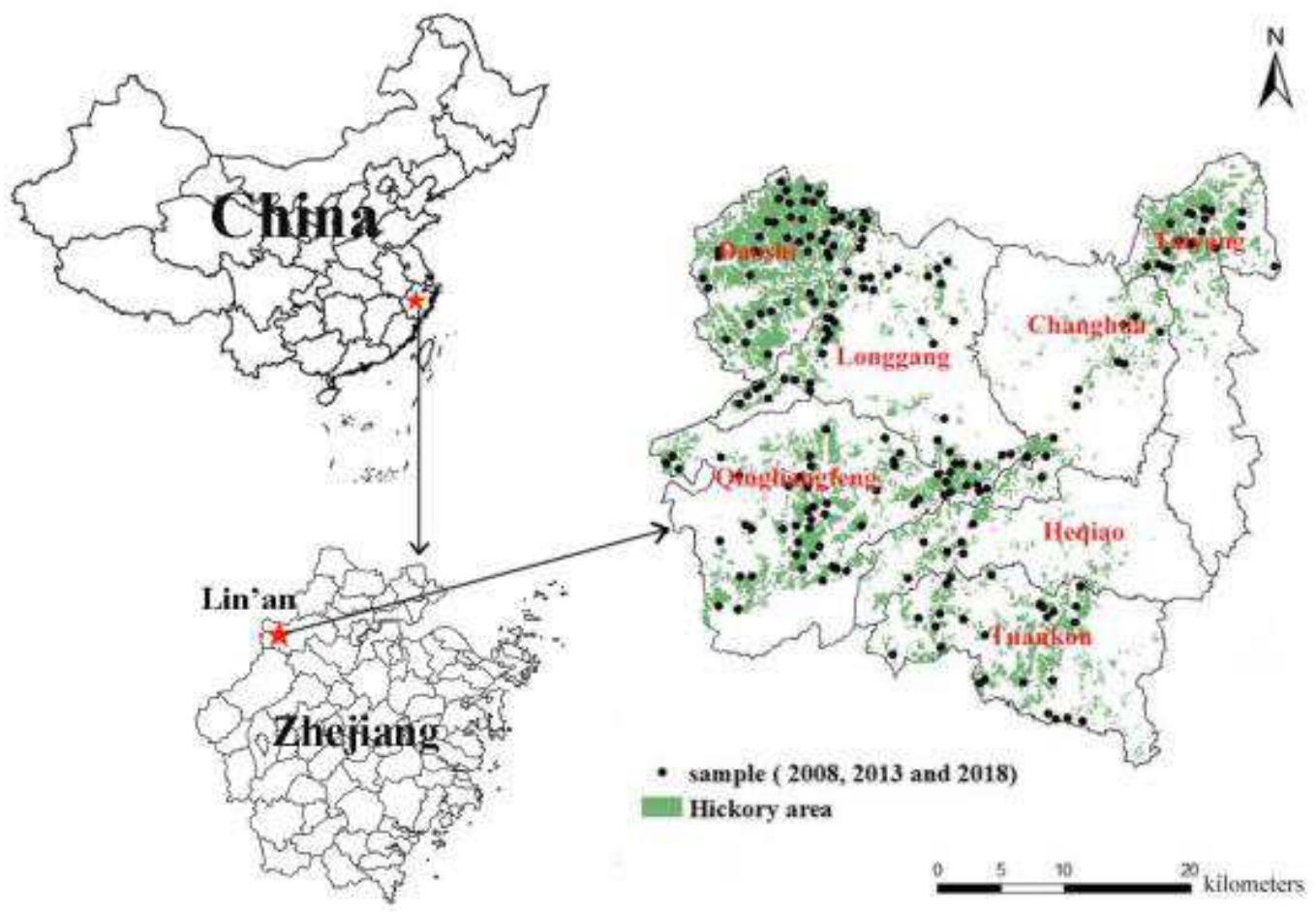

518

519

520

521

522

523

Figure 1. Location of the study area in Lin'an city, Zhejiang Province, China.
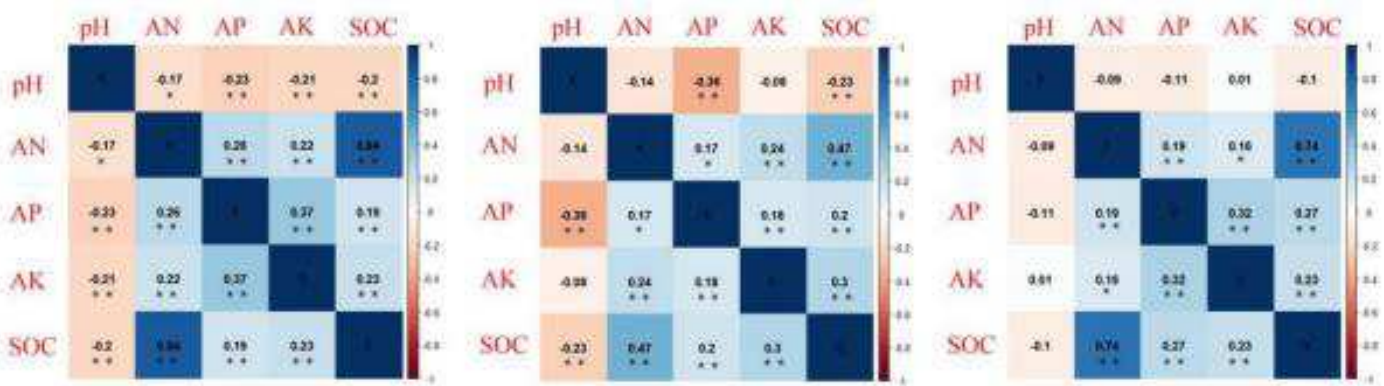

525 Figure 2. Pearson correlation among soil properties in 2008, 2013 and 2018. Color depicts the

526 direction of the correlation (blue $=$ positive, red $=$ negative). $\mathrm{P}$-values in black color are significant $(*$ $527 \mathrm{P}<0.05, * * \mathrm{P}<0.01)$. The correlation coefficients are shown in the panel. AN: available nitrogen; AP: available phosphorus; AK: available potassium; SOC: soil organic carbon. 
(a) $\mathrm{pH} 2008$ Moran's $/=0.31$

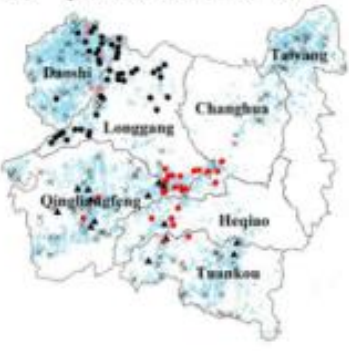

(d) AN 2008 Moran's $I=0.07$

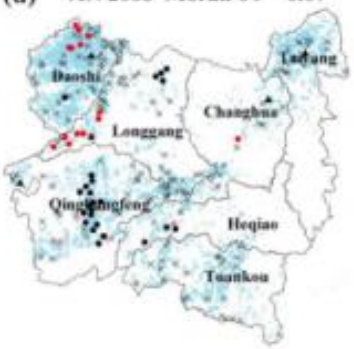

(g) AP 2008 Moran's $I=0.26$

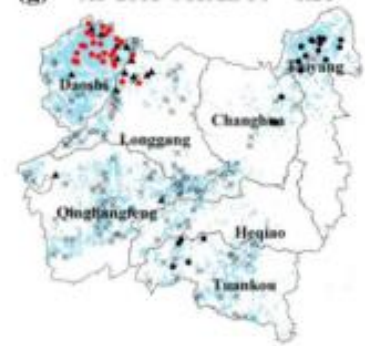

(j) AK 2008 Moran's $t=\mathbf{0 . 2 2}$

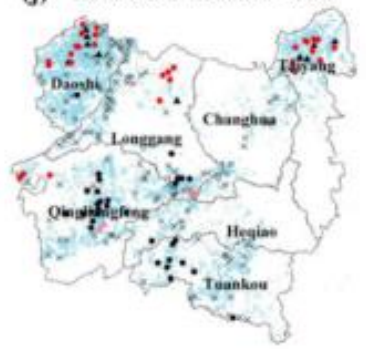

(m) SOC 2008 Moran's $/=0.13$

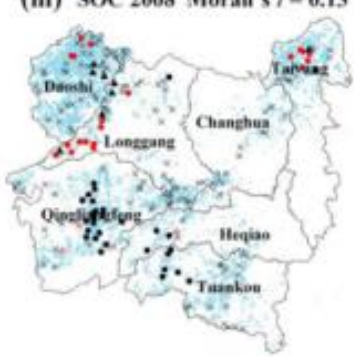

- High - High Cluster

- Low - Low Cluster (b) $\mathrm{pH} 2013$ Moran's $/=0.16$

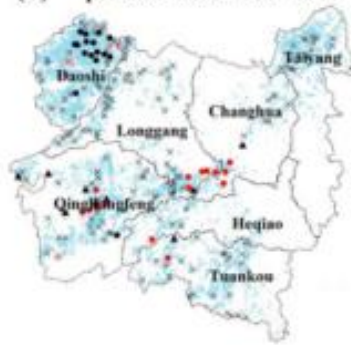

(e) AN 2013 Moran's $l=0.05$

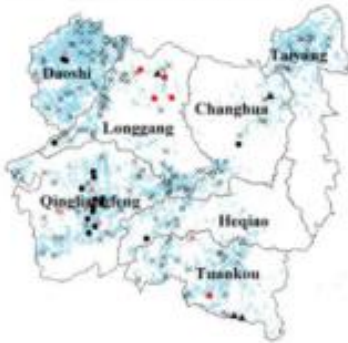

(h) AP 2013 Meran's $/=0.19$

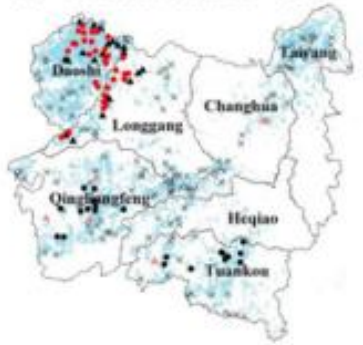

(k) AK 2013 Meran's $t=0.14$

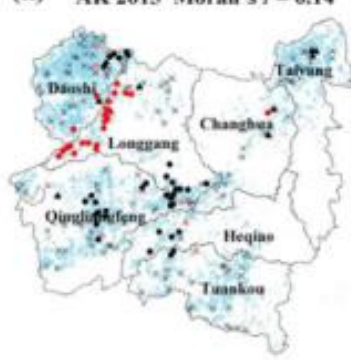

(n) $\operatorname{SOC} 2013$ Moran's $I=0.14$

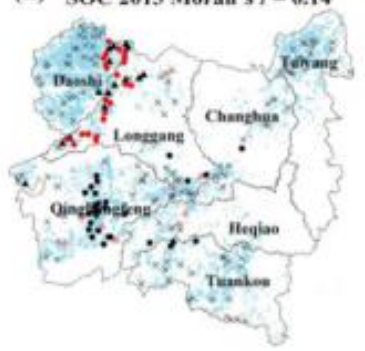

$\times$ No-Signiffcant

High - Low Outlier

- Low - High Outlier

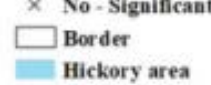

(c) pH 2018 Moran's $I=0.16$

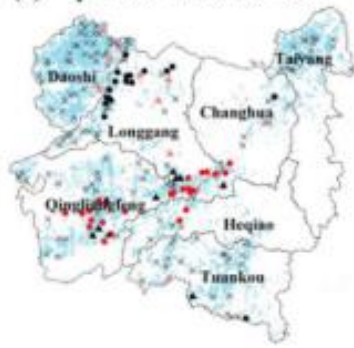

(f) AN 2018 Moran's $/=0.09$

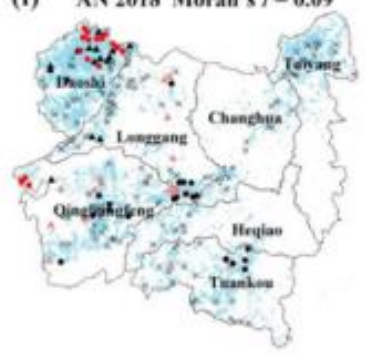

(i) AP 2018 Moran's $I=0.13$

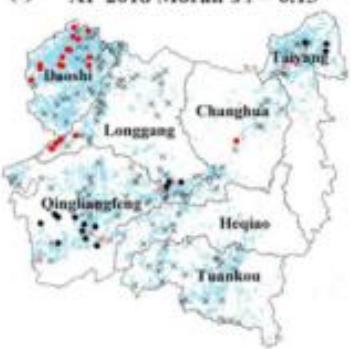

(I) AK 2018 Moran's $f=0.10$

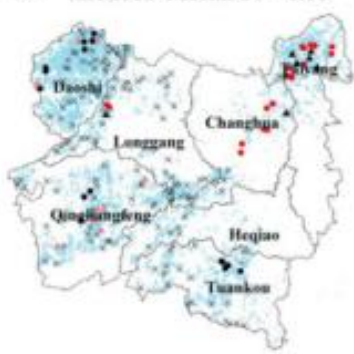

(o) SOC 2018 Moran's $I=0.17$

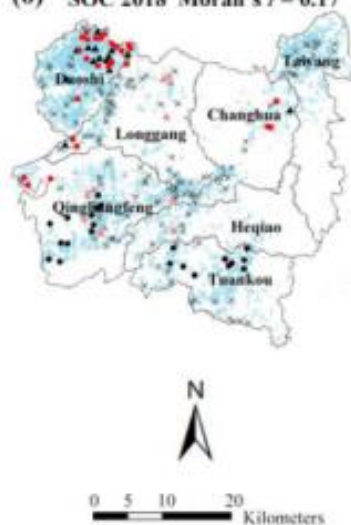

Figure 3. Local indicators of spatial correlation (LISA) maps of soil properties in Chinese hickory plantation regionss. AN: available nitrogen; AP: available phosphorus; AK: available potassium; SOC: soil organic carbon. 

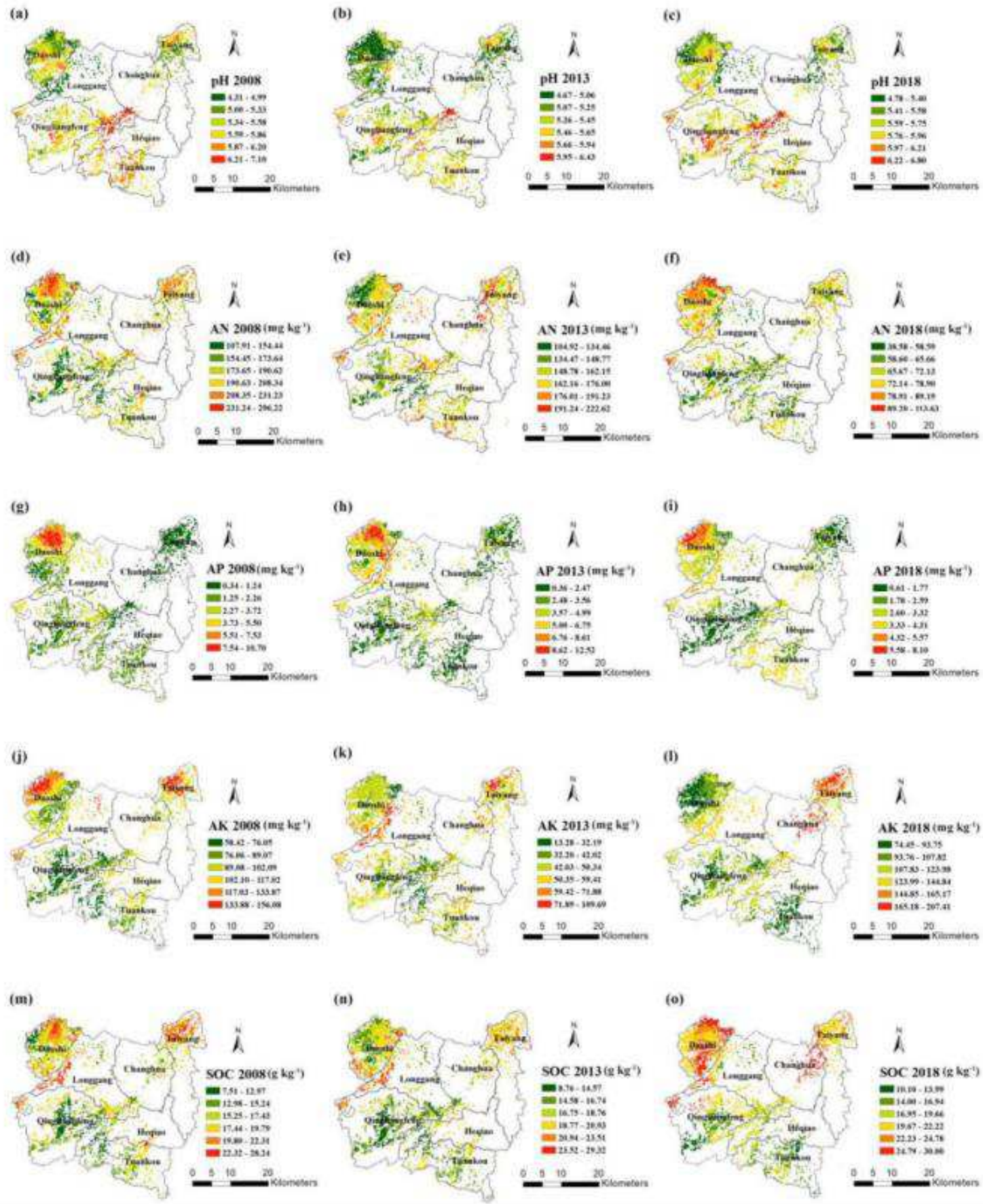

535 Figure 4. Spatial distribution maps of soil properties in Chinese hickory plantation regions. AN:

536 available nitrogen; AP: available phosphorus; AK: available potassium; SOC: soil organic carbon. 
(a)

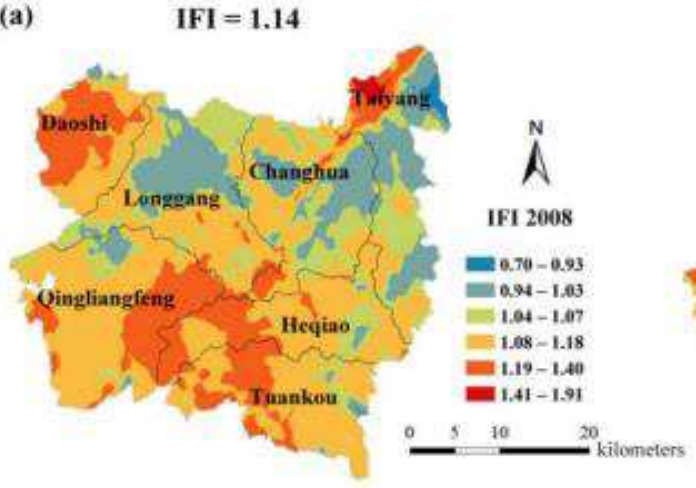

(b) $\quad$ IFI $=1.08$

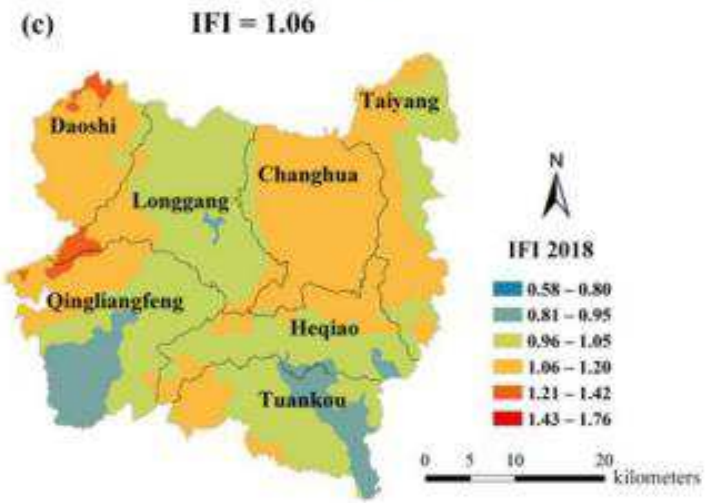

539

\section{0}

541

542

543

544

545

546

547

548

549

550

551

552

553

554

555

556

557

558

559

560

561

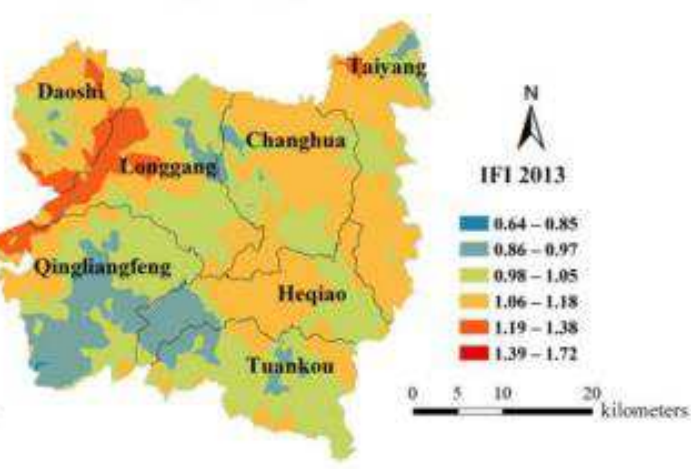

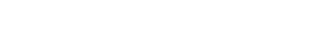


562 Table 1 Descriptive statistics of the soil attributes.

\begin{tabular}{|c|c|c|c|c|c|c|c|c|c|}
\hline Attributes & Year & Minimum & Maximum & Range & $\mathrm{CV} \%$ & Mean \pm SD & Skewness & Kurtosis & $K-S_{p}$ \\
\hline \multirow{3}{*}{$\mathrm{pH}$} & 2008 & 4.09 & 7.58 & 3.49 & 13.07 & $5.51 \pm 0.72 b$ & 0.241 & -0.244 & $0.016(0.2)$ \\
\hline & 2013 & 4.26 & 7.12 & 2.86 & 10.92 & $5.31 \pm 0.58 \mathrm{c}$ & 0.038 & -0.232 & $0.000(0.2)$ \\
\hline & 2018 & 4.50 & 7.35 & 2.85 & 10.23 & $5.77 \pm 0.59 \mathrm{a}$ & 0.015 & -0.144 & $0.000(0.2)$ \\
\hline \multirow{3}{*}{$\mathrm{AN}\left(\mathrm{mg} \mathrm{kg}^{-1}\right)$} & 2008 & 83.69 & 375.10 & 291.41 & 31.97 & $190.08 \pm 60.76 \mathrm{a}$ & -0.018 & -0.345 & $0.030(0.2)$ \\
\hline & 2013 & 36.21 & 348.30 & 312.09 & 32.21 & $171.12 \pm 55.12 b$ & 0.006 & -0.125 & $0.000(0.2)$ \\
\hline & 2018 & 24.50 & 147.31 & 122.81 & 32.54 & $71.89 \pm 23.39 \mathrm{c}$ & -0.122 & 0.151 & $0.001(0.2)$ \\
\hline \multirow{3}{*}{$\mathrm{AP}\left(\mathrm{mg} \mathrm{kg}{ }^{-1}\right)$} & 2008 & 0.04 & 21.20 & 21.16 & 129.60 & $3.75 \pm 4.86 \mathrm{~b}$ & 0.022 & -0.405 & $0.000(0.2)$ \\
\hline & 2013 & 0.10 & 15.84 & 15.74 & 82.50 & $4.40 \pm 3.63 \mathrm{a}$ & -0.694 & 1.122 & $0.000(0.2)$ \\
\hline & 2018 & 0.06 & 15.44 & 15.38 & 91.25 & $4.00 \pm 3.65 \mathrm{ab}$ & 0.064 & -0.502 & $0.000(0.2)$ \\
\hline \multirow{3}{*}{$\mathrm{AK}\left(\mathrm{mg} \mathrm{kg}{ }^{-1}\right)$} & 2008 & 31.21 & 246.09 & 214.88 & 46.86 & $101.37 \pm 47.50 \mathrm{a}$ & 0.064 & -0.502 & $0.000(0.2)$ \\
\hline & 2013 & 5.96 & 140.08 & 134.12 & 54.79 & $50.98 \pm 27.93 b$ & 0.157 & -0.312 & $0.000(0.2)$ \\
\hline & 2018 & 22.06 & 340.39 & 318.33 & 60.78 & $114.60 \pm 69.65 \mathrm{a}$ & -0.054 & -0.747 & $0.000(0.1)$ \\
\hline \multirow{3}{*}{$\mathrm{SOC}\left(\mathrm{g} \mathrm{kg}^{-1}\right)$} & 2008 & 3.06 & 42.42 & 39.36 & 40.28 & $18.32 \pm 7.38 b$ & -0.398 & 0.687 & $0.000(0.2)$ \\
\hline & 2013 & 6.06 & 38.66 & 32.60 & 34.62 & $18.34 \pm 6.35 b$ & -0.153 & -0.051 & $0.006(0.2)$ \\
\hline & 2018 & 3.14 & 46.96 & 43.82 & 38.92 & $21.30 \pm 8.29 \mathrm{a}$ & -0.735 & 1.285 & $0.028(0.08)$ \\
\hline
\end{tabular}

AN: available nitrogen; AP: available phosphorus; AK: available potassium; SOC: soil organic carbon. Different letters in the same variable indicate significant differences among years at $P<0.05$ level. $\mathrm{CV}$ : coefficient of variation; $K-S_{p}$ : significance level of Kolmogorov-Smirnov test for normality. The $K-S p$ values in brackets were calculated after transformation. 
Table 2 Theoretical semi-variance models and their corresponding parameters of soil properties in $567 \quad 2008,2013$ and 2018.

\begin{tabular}{cccccccc}
\hline \multirow{2}{*}{ Attributes } & $\begin{array}{c}\text { Theoretical } \\
\text { model }\end{array}$ & Year & $\begin{array}{c}\text { Nugget } \\
\left(\mathrm{C}_{0}\right)\end{array}$ & $\begin{array}{c}\text { Sill } \\
\left(\mathrm{C}_{0}+\mathrm{C}\right)\end{array}$ & $\begin{array}{c}\text { Nugget/Sil } \\
1\end{array}$ & $\begin{array}{c}\text { Range } \\
(\mathrm{km})\end{array}$ & $\mathrm{R}^{2}$ \\
\hline \multirow{3}{*}{$\mathrm{pH}$} & Exponential & 2008 & 0.36 & 0.71 & 0.51 & 40.70 & 0.91 \\
& Exponential & 2013 & 0.16 & 0.32 & 0.50 & 3.39 & 0.85 \\
$\mathrm{AN}\left(\mathrm{mg} \mathrm{kg}^{-1}\right)$ & Gaussian & 2018 & 0.07 & 0.35 & 0.20 & 0.19 & 0.75 \\
& Exponential & 2008 & 1606.00 & 3642.00 & 0.44 & 2.16 & 0.76 \\
& Exponential & 2013 & 2845.30 & 3393.14 & 0.84 & 4.82 & 0.73 \\
& Exponential & 2018 & 111.00 & 633.80 & 0.18 & 0.13 & 0.50 \\
$\mathrm{AP}\left(\mathrm{mg} \mathrm{kg}^{-1}\right)$ & Exponential & 2008 & 2.70 & 25.74 & 0.10 & 0.16 & 0.87 \\
& Gaussian & 2013 & 1.92 & 12.79 & 0.15 & 1.61 & 0.64 \\
& Linear & 2018 & 1.54 & 1.88 & 0.82 & 23.73 & 0.80 \\
$\mathrm{AK}\left(\mathrm{mg} \mathrm{kg}^{-1}\right)$ & Exponential & 2008 & 1972.40 & 2784.92 & 0.71 & 0.85 & 0.85 \\
& Exponential & 2013 & 517.67 & 737.80 & 0.70 & 5.18 & 0.78 \\
& Exponential & 2018 & 1490.00 & 4981.00 & 0.30 & 3.78 & 0.81 \\
$\mathrm{SOC}\left(\mathrm{g} \mathrm{kg}^{-1}\right)$ & Gaussian & 2008 & 42.60 & 85.21 & 0.50 & 17.42 & 0.88 \\
& Gaussian & 2013 & 34.00 & 68.01 & 0.50 & 23.21 & 0.84 \\
& Gaussian & 2018 & 0.10 & 65.99 & 0.002 & 5.40 & 0.91 \\
\hline
\end{tabular}

568 AN: available nitrogen; AP: available phosphorus; AK: available potassium; SOC soil organic carbon. 


\section{Supplementary Files}

This is a list of supplementary files associated with this preprint. Click to download.

- Supplementarymaterial.pdf 